\title{
Author Correction: Determination of isoform-specific RNA structure with nanopore long reads
}

Jong Ghut Ashley Aw D, Shaun W. Lim, Jia Xu Wang (iD, Finnlay R. P. Lambert, Wen Ting Tan, Yang Shen, Yu Zhang (D, Pornchai Kaewsapsak, Chenhao Li DD, Sarah B. Ng, Leah A. Vardy (D), Meng How Tan, Niranjan Nagarajan (D) and Yue Wan

Correction to: Nature Biotechnology https://doi.org/10.1038/s41587-020-0712-z, published online 26 October 2020.

In the version of this article initially published online, a second affiliation and an acknowledgment were missing for author Finnlay R. P. Lambert. The author is affiliated with the Division of Biomedical Sciences, Warwick Medical School, University of Warwick, Coventry, UK, and was supported by a doctoral scholarship from the Warwick-A^STAR research attachment programme. The errors have been corrected in the print, PDF and HTML versions of the article.

Published online: 12 November 2020

https://doi.org/10.1038/s41587-020-00755-w

(c) The Author(s), under exclusive licence to Springer Nature America, Inc. 2020

\section{Publisher Correction: First small-molecule drug targeting RNA gains momentum}

Cormac Sheridan

Correction to: Nature Biotechnology https://doi.org/10.1038/s41587-020-00788-1, published online 11 January 2021.

In the version of this article initially published, as a result of an editing error, we said that Spinraza (nusinersen) "requires a child to be pulled from school for a month beforehand to prevent any illness that would render the necessary anesthesia unsuitable for the child." We should have said that "as this requires anesthesia, reports have circulated that some parents have elected to pull their children from school for a month beforehand to prevent any illness that might compromise the procedure." The error has been corrected in the PDF and HTML versions of the article.

Published online: 4 February 2021

https://doi.org/10.1038/s41587-021-00841-7

(c) The Author(s), under exclusive licence to Springer Nature America, Inc. 2021

\section{Publisher Correction: Light-activated genetic therapy to treat blindness enters clinic}

Mark Ratner

Correction to: Nature Biotechnology https://doi.org/10.1038/s41587-021-00823-9, published online 9 February 2021.

In the version of this article initially published, the image was credited to John Flannery, UC Berkeley. The correct credit is as follows: Reprinted with permission from B. Roska \& J.-A. Sahel, Nature https://doi.org/10.1038/s41586-018-0076-4 (2018), Springer Nature. The error has been corrected in the PDF and HTML versions of the article.

Published online: 1 March 2021

https://doi.org/10.1038/s41587-021-00871-1

(c) The Author(s), under exclusive licence to Springer Nature America, Inc. 2021 